\title{
The role of c-Src in integrin (a6ß34) dependent translational control
}

\author{
Young Hwa Soung ${ }^{1}$, Nadejda Korneeva ${ }^{2}$, Tae Hyong Kim ${ }^{3}$ and Jun Chung ${ }^{\text {** }}$
}

\begin{abstract}
Background: Integrin a6ß4 contributes to cancer progression by stimulating transcription as well as translation of cancer related genes. Our previous study demonstrated that $a 6 \beta 4$ stimulates translation initiation of survival factors such as VEGF by activating mTOR pathway. However, the immediate early signaling events that link a6ß4 to mTOR activation needs to be defined.

Results: In the current studies, we demonstrated that c-Src is an immediate early signaling molecule that acts upstream of a6 34 dependent mTOR activation and subsequent translation of VEGF in MDA-MB-435/ 34 and MDAMB-231 cancer cells. $\mathrm{m}^{7}$ GTP-Sepharose-binding assay revealed that Src activity is required to form elF4F complex which is necessary for Cap-dependent translation in a6ß4 expressing human cancer cells.
\end{abstract}

Conclusions: Overall, our studies suggest that integrin $\beta 4$ and c-Src activation is important early signaling events to lead mTOR activation and cap-dependent translation of VEGF.

Keywords: c-Src, Integrin, Translation, mTOR, VEGF

\section{Background}

Cancer cells must acquire survival advantages including growth signaling autonomy, apoptosis resistance, sustaining of angiogenesis under stress conditions such as nutrient and oxygen deprivation to successfully survive in tumor microenvironment [1]. Although these complicated processes involves regulation of survival related gene expression both at the transcription and translational level, recent evidence suggest that translation initiation is a primary check point that regulates cancer related mRNAs [2]. One of the major mechanisms that cancer cells maintain higher efficiency of translation initiation involves stimulation of translation initiation factor, eIF4E [3,4].

eIF4E is the rate limiting factor responsible for delivering cellular mRNAs to eIF4F complex (eIF4E, a scaffold protein eIF4G and a RNA helicase eIF4A) through interaction with the $5^{\prime}$-terminal $\left(\mathrm{m}^{7} \mathrm{GpppN}\right)$ Cap structure of mRNAs [5]. Most of the cancer related mRNAs have the highly complex and lengthy 5' untranslated region, which leads to the low translation initiation efficiency

\footnotetext{
* Correspondence: Jun-Chung@ouhsc.edu

${ }^{1}$ Department of Physiology and Stephenson Cancer Center, The University of Oklahoma Health Science Center, Oklahoma City, Oklahoma 73104, USA Full list of author information is available at the end of the article
}

[6]. Therefore, either level or activity of eIF4E needs to be up regulated to maintain active translation of these weak mRNAs. One way to enhance eIF4E activity is through PI3-K/Akt dependent signaling cascade that activates mTOR kinase [7]. Activated mTOR phosphorylates and inactivates eIF4E-binding protein 4E-BP [7]. Upon phosphorylation of $4 \mathrm{E}-\mathrm{BP}$, eIF4E is released from $4 \mathrm{E}-\mathrm{BP}$ and bind to eIF4G to form eIF4F complex which mediates translation initiation $[7,8]$. Aggressive cancer cells often take advantage of mitogenic signaling pathways to activate mTOR and free up eIF4E to maintain their survival and growth [9-11].

Our previous studies demonstrated that $\alpha 6 \beta 4$ integrin stimulates eIF4E activity to promote translation of survival factor, VEGF via Akt/mTOR pathway in breast carcinoma cells under serum deprivation condition $[12,13]$. While $\alpha 6 \beta 4$-dependent translation control via ATK/ mTOR pathway has been established, the early signaling event to link between $\alpha 6 \beta 4$ and mTOR is not well characterized. One of the prime candidates that mediate $\alpha 6 \beta 4$ dependent mTOR activation is Src as it is a key immediate early downstream effector of $\alpha 6 \beta 4$ and its activity is required for $\alpha 6 \beta 4$ signaling competency $[14,15]$. Src is an intracellular non-receptor tyrosine kinase which has been implicated in proliferation, metastasis 
and invasion of various human cancers [16,17]. For example, oestrogen induced c-Src activation leads to 4EBP phoshorylation through PI3K/mTOR pathway and consequently promotes translation of HIF- $1 \alpha$ in breast cancer cells [18]. Another study showed that active c-Src up-regulates translation of $\beta$-catenin by activation of eIF4E via Ras/ERK pathway and the phosphorylation of $4 \mathrm{E}-\mathrm{BP}$ via the PI3K/mTOR pathways [19] Based on these evidences that $\mathrm{c}$-Src stimulate translational initiation via mTOR signaling, we hypothesized that $\mathrm{c}-\mathrm{Src}$ mediates $\alpha 634$ dependent mTOR activation and subsequent assembly of eIF4E machinery to enhance capdependent translation of weak mRNAs.

In this study, we assessed the role of c-Src in $\alpha 6 \beta 4$ dependent translational control. Pharmacologic inhibition of c-Src as well as knockdown of its expression by shRNA showed that c-Src plays an essential role in mediating

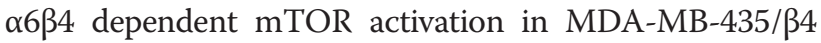
and MDA-MB-231 cancer cells. Src is also required to form eIF4F complex and enhance cap-dependent translation of VEGF mRNA. These results suggest that c-Src is an important immediate early signaling molecule to connect $\alpha 6 \beta 4$ signaling to mTOR, which eventually contribute to translation of survival factors such as VEGF.

\section{Results}

\section{Src activity is required for a6 $\beta 4$ dependent mTOR} phosphorylation

$\alpha 6 \beta 4$ plays a pivotal role in controlling translation through mTOR signaling [13], but the immediate early signaling events that link $\alpha 6 \beta 4$ to mTOR activation remains to be defined. Based on recent reports that c-Src is involved in translation initiation through $\mathrm{AKT} / \mathrm{mTOR}$ signaling in human cancer cells $[18,19]$, we hypothesized that $\mathrm{c}-\mathrm{Src}$ is a major mediator for $\alpha 6 \beta 4$ dependent mTOR activation. To test this hypothesis, we first assessed the relationship between $\alpha 6 \beta 4$ expression and Src activity. We stably knocked down $\beta 4$ integrin expression in MDA-MB-231 using lentivirus shRNA. MDAMB-435 cells, which endogenously lack $\beta 4$ expression, were stably transfected with either $\beta 4$ integrin or mock vector (Figure 1A). As reported previously by our studies and others $[14,20]$, the reduction of $\beta 4$ integrin expression by $\beta 4$ shRNA in MDA-MB-231 cells effectively blocked Src phosphorylation at Y416 (an indicator of Src activation) and $\beta 4$ phosphorylation at Y1494 (an indicator of $\beta 4$ integrin activation) (Figure 1A. left panel). The exogenous $\beta 4$ integrin expression in MDA-MB-435 cells (MDA-MB-435/ק4) significantly increased the Src phosphorylation at Y416 (Figure 1A. right panel). We then tested the role of Src in $\alpha 6 \beta 4$ dependent mTOR phosphorylation. Pharmacologic inhibition of Src activity by PP2 effectively decreased phosphorylation level of mTOR at Ser2448 (an indicator of mTOR activity) in
MDA-MB-231 and MDA-MB-435/ 34 cells (Figure 1B). To further confirm the role of Src in $\alpha 6 \beta 4$ dependent mTOR phosphorylation, we knocked down expression of c-Src using shRNA in MDA-MB-231 and MDA-MB$435 / \beta 4$ cells. Knockdown of c-Src expression significantly reduces the level of phosphorylated mTOR at S2448 too (Figure 1C). We were not able to detect a significant change of the total protein level of mTOR by inhibition of Src by PP2 or shRNA. These data suggest that $\alpha 6 \beta 4$ dependent c-Src activation leads to the phosphorylation of mTOR.

\section{c-Src contributes to a6 34 dependent TORC1 and TORC2 activation}

Mammalian target of rapamycin (mTOR) exists in two functionally and structurally distinct complexes, TORC1 and TORC2 [21]. The primary function of TORC1 is to regulate translation initiation through the phosphorylation of S6K and 4EBP1, whereas the primary function of TORC2 is to regulate survival and proliferation by activation of the kinases such as AKT and SGK $[21,22]$. To assess relative contribution of $\mathrm{c}-\mathrm{Src}$ in TORC1 vs. TORC2 activation, we tested the effects of c-Src inhibition on $\alpha 6 \beta 4$ dependent Akt phosphorylation at Ser 473 (an indicator of TORC2 activity) and phosphosrylation of S6 ribosomal protein at Ser235/236 and 4E-BP1 at Ser65 (indicators of TORC1 activity) in MDA-MB-231 and MDA-MB-435/ $\beta 4$ cells. Inhibition of c-Src activity by PP2 (Figure 2A) as well as c-Src expression by shRNA (Figure 2B) effectively reduced the level of phosphorylated AKT (on Ser473), S6 ribosomal protein (on Ser235/236) and 4E-BP1 (on Ser65). These results suggest that c-Src mediates $\alpha 6 \beta 4$ dependent TORC1 and TORC2 activation.

\section{Inhibition of c-Src blocks $a 6 \beta 4$ dependent translation of VEGF mRNA}

We then assessed the effects of c-Src inhibition on the efficiency of overall translation initiation in MDA-MB231 and MDA-MB-435//4 cells by performing polysome analysis (Figure 3 ). The mRNA was isolated from these cells in the presence of either DMSO or PP2, and then fractionated on a sucrose gradient. As shown in Figure 3, the polysome analysis separates untranslated complex (fraction 1 through 3), light polysomes (fraction 4 through 8; poorly translated mRNAs) and heave polysomes (fraction 9 through 12; efficiently well-translated mRNAs). Our previous studies demonstrated that expression of $\beta 4$ integrin increases the pool of heavy polysomes in these cells [13,21]. The inhibition of $\mathrm{Src}$ activity by PP2 dramatically reduced the amount of heavy polysomes (Figure 3), suggesting that Src is required for $\alpha 6 \beta 4$ dependent translation initiation. Next, we tested the role of Src in $\alpha 6 \beta 4$ dependent VEGF 


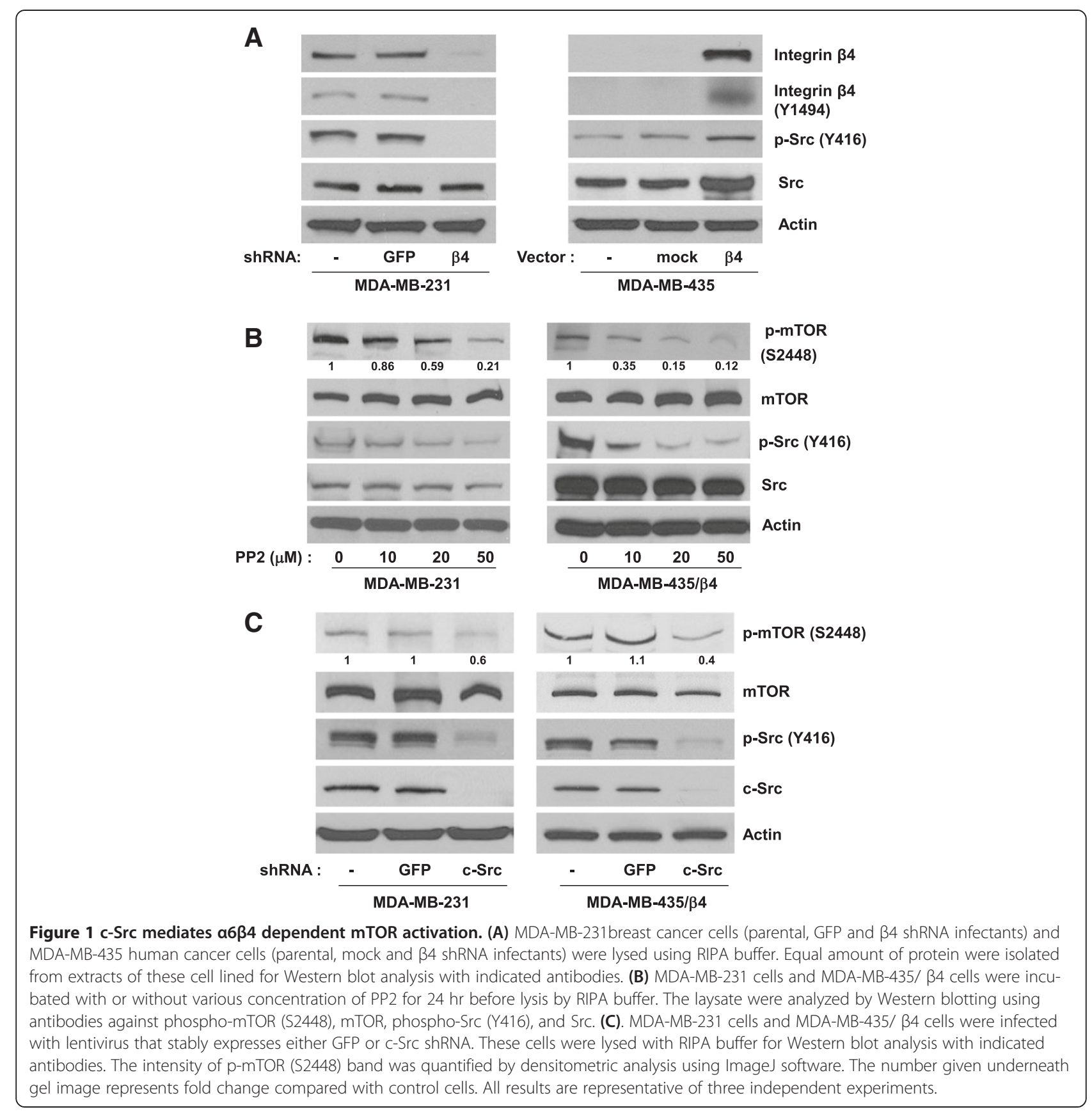

translation. The relative amount of VEGF mRNA in each polysomal fraction was analyzed by qRT-PCR. In the MDA-MB-231 and MDA-MB-435/ß4 (Figure 4), VEGF mRNA is distributed mostly in the polysomal region ( $\mathrm{L}$ and $\mathrm{H}$, fractions \#4-12). Both PP2 inhibition of Src activity (Figure 4A) and c-Src knockdown by shRNA (Figure 4B) effectively shifted the distribution of VEGF mRNA to untranslated complexes (U, fractions \#1-3). This result indicates that $\mathrm{c}$-Src inhibition affects cap dependent translation initiation of weak mRNAs such as VEGF.
Inhibition of Src prevents assembly of elF4F complexes

Since cap-dependent translational efficiency of weak mRNAs such as VEGF is determined by activity of eIF4E and the eIF4F complexes, we examined the role of $\mathrm{c}$-Src in eIF4E-binding to eIF4F components such as eIF4E and eIF4G. We performed $\mathrm{m}^{7} \mathrm{GTP}$-Sepharose pull down assay in MDA-MB-435/ $\beta 4$ cells to test whether Src inhibition modulates the interaction of eIF4E with eIF4G (an indicator of active translation) or 4E-BP1 (an indicator of inactive translation). The inhibition of Src by PP2 (Figure 5A) and c-Src knockdown by shRNA (Figure 5B) 


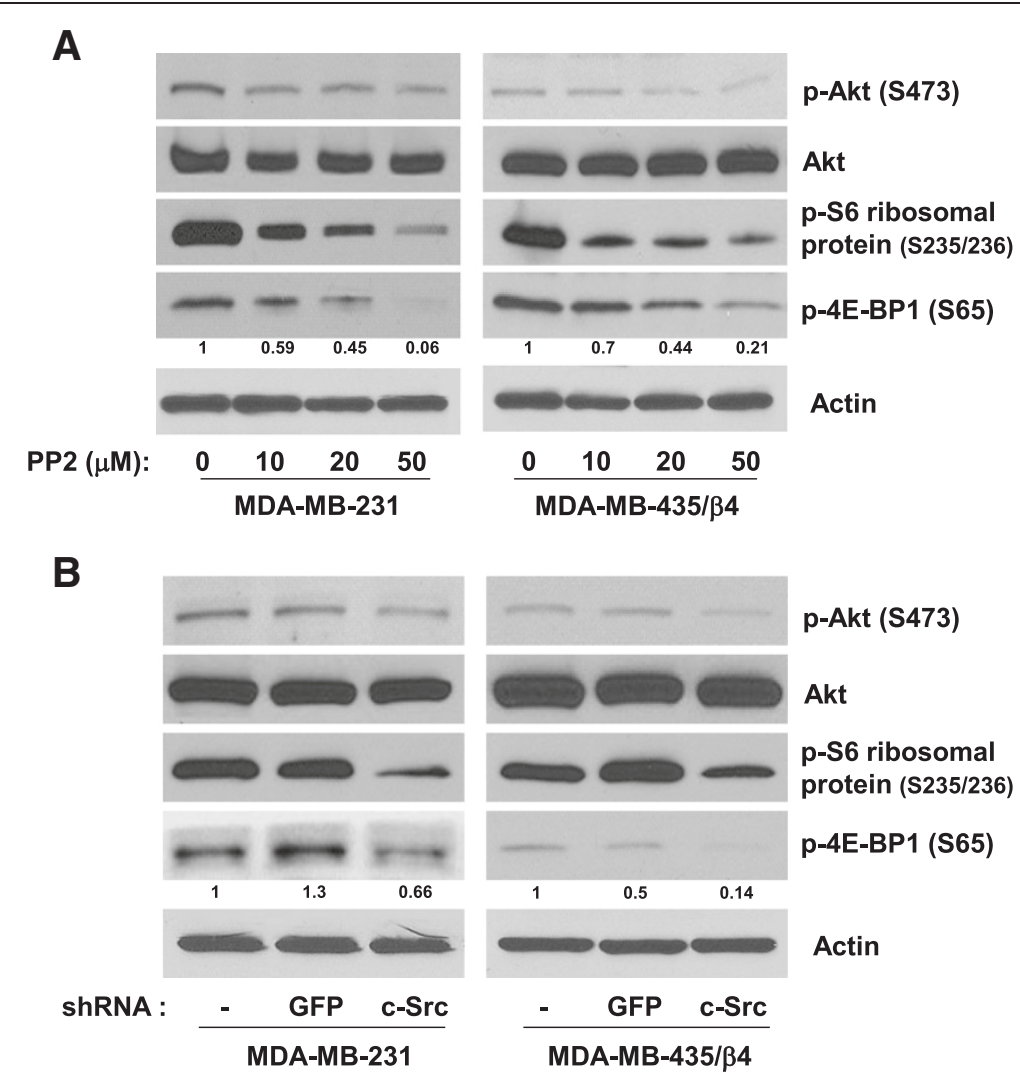

Figure 2 c-Src is required for a6 $\beta 4$ dependent TORC1 and TORC2 activation. (A) MDA-MB-231 cells and MDA-MB-435/ $\beta 4$ cells were incubated with DMSO and indicated concentrations of PP2 for $24 \mathrm{hr}$ before lysis by RIPA buffer. Equal amount of protein were isolated and analyzed by Western blotting using antibodies against phospho-AKT (S473), AKT, phospho-S6 ribosomal protein (S235/236), and phospho-4E-BP1 (S65). (B) Equal lysates from MDA-MB-231 cells and MDA-MB-435/ $\beta 4$ cells expressing shRNA against GFP or c-Src were analyzed by Western blotting with indicated antibodies. The intensity of $\mathrm{p}-4 \mathrm{E}-\mathrm{BP} 1$ (S65) band was quantified by densitometric analysis using ImageJ software. The number given underneath gel image represents fold change compared with control cells. All results are representative of three independent experiments.

effectively decreased the levels of eIF4G binding to $\mathrm{m}^{7} \mathrm{GTP}$, whereas the binding level of $4 \mathrm{E}-\mathrm{BP} 1$ to eIF4E is increased. These data suggests that the inhibition of Src disrupts the assembly of eIF4F complex by inducing the binding of 4E-BP1 to eIF4E, and by disassociating eIF4G from eIF4E.

\section{Discussion}

A number of studies demonstrated the role of integrins in translation of survival and growth factors through enhancing eIF4E function [12], but the exact mechanism by which integrins control translation initiation of cancer related mRNAs remains to be determined. In the previous study, we showed that $\alpha 6 \beta 4$ integrin promotes the translation of VEGF mRNA through the AKT/ mTOR/eIF4E signaling axis [13]. In the current studies, we investigated the role of c-Src as an immediate early signaling effector that mediates $\alpha 6 \beta 4$ dependent mTOR activation. We provided evidence that $\mathrm{c}$-Src inhibition by PP2 or shRNA blocks mTOR pathway and the subsequent assembly of eIF4F complexes. This is first report to define the early signaling event that link between $\alpha 6 \beta 4$ and mTOR pathway.

Our studies indicated that $\mathrm{c}-\mathrm{Src}$ is one of early $\alpha 6 \beta 4$ signaling effectors that mediate mTOR activation. As cSrc represents one isoform of Src Family Kinases (SFKs), it is possible that other isoform of SFKs could play a role in $\alpha 6 \beta 4$ dependent mTOR activation. This is more likely due to the previous report that Fyn becomes activated to mediate $\alpha 6 \beta 4$ dependent pro-invasive migration of breast carcinoma cells [23]. $\alpha 6 \beta 4$ dependent Fyn activation requires the recruitment of SHP2 to the phosphorylated cytoplasmic domain of integrin $\beta 4$ [23]. It remains to be seen whether $\alpha 6 \beta 4$ dependent c-Src activation also requires the involvement of SHP2. Another possibility is the involvement of Focal Adhesion Kinase (FAK) in cSrc activation. FAK was shown to be activated by $\alpha 6 \beta 4$ [24] and FAK mediates Src activation in integrin signaling such as $\alpha 5 \beta 1$ or $\alpha 4 \beta 1$ [25]. If we establish the mechanism by which a6b4 activates multiple isoforms of SFKs including Fyn and c-Src, we may need to perform sequential knockdown of each SFK isoform expression by 

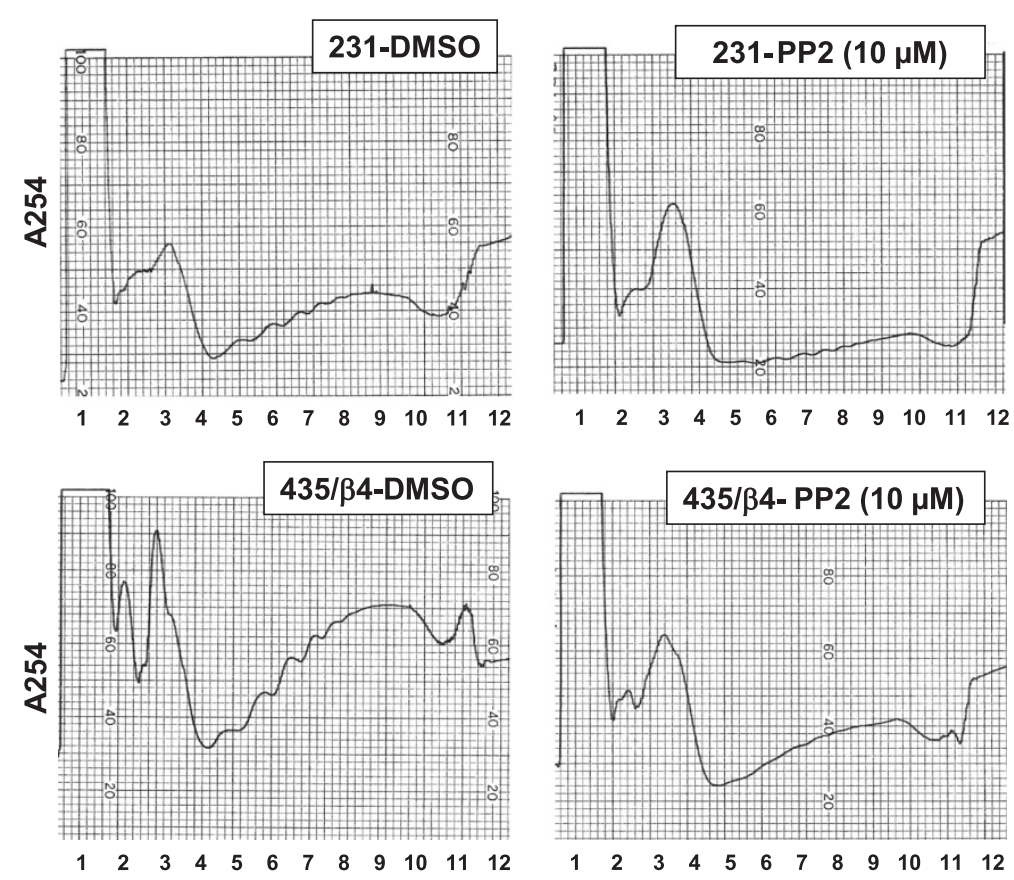

Figure 3 The effect of Src inhibition on translation initiation. MDA-MB-231 cells and MDA-MB-435/ $\beta 4$ cells were treated with DMSO or 10 MM PP2 for $24 \mathrm{hr}$. Cell lysates were separated into 12 fractions on sucrose gradients as described in the Methods. The distribution was continuously recorded by absorbance at $A_{254} \mathrm{~nm}$. The polysome profiles were showed as peaks. 1 through 7 represents light polysomes (untranslated mRNA and initiation complex) and 8 through 12 represents heavy polysomes (translated mRNA). Numbers indicates fraction numbers. The results are obtained from three independent experiments.

shRNAs to test the role of other SFKs in mTOR activation. The assays will test whether multiple SFK isoform synergistically contribute to $\alpha 6 \beta 4$ dependent mTOR activation, or the loss of one SFK isoform could simply be compensated by others.

While our current studies mostly focused on translation initiation aspects of mTOR signaling (mostly through TORC1 pathway), TORC2 pathway is likely activated by $\alpha 6 \beta 4 / \mathrm{c}-$ Src signaling axis (Figure $2 \mathrm{~B}$ ). Enhancement of eIF-4E function by $\alpha 6 \beta 4$ is known to be mediated by TORC1 pathway as we previously showed that TORC1 specific inhibitor, rapamycin blocked $\alpha 6 \beta 4$ dependent eIF-4E activation [13]. It remains to be determined how TORC2 signaling pathway contributes to

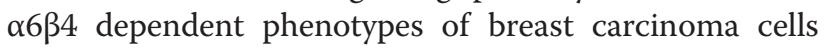
such proliferation, survival, cell motility and invasion. Knockdown of TORC2 specific components such as Rictor or Sin1 $[26,27]$ will address this issue.

It is currently unknown how activated c-Src by $\alpha 6 \beta 4$ mediates downstream signaling events leading to mTOR activation. Both Akt and MAPK seem to be prime candidates in mediating $\mathrm{c}$-Src dependent mTOR activation as both involves 4E-BP1 phosphorylation, which is a key event for mTOR activation $[19,28]$. Activated Src was shown to mediate both Akt [29] and MAPK [30]. Alternatively, c-Src could enhance the functional crosstalk between $\alpha 6 \beta 4$ and growth factor receptors such as EGFR and c-Met [31] and this interaction was shown to enhance both Akt [32] and MAPK signaling [33]. All these evidences suggest that $\mathrm{c}$-Src could be an important therapeutic target that could affect growth factor receptor signaling as well as downstream events such as mTOR signaling. Considering that the role of $\alpha 6 \beta 4$ in breast carcinoma progression is well established, but no therapeutic agent against $\alpha 6 \beta 4$ is available yet, targeting Src activity will merit consideration against tumors that express high levels of $\alpha 6 \beta 4$.

\section{Conclusions}

In conclusion, we defined that c-Src is an immediate early signaling molecule that connects $\alpha 6 \beta 4$ to mTOR signaling axis. c-Src mediates $\alpha 6 \beta 4$ dependent mTOR activation and subsequent enhancement of cap-dependent translation of weak mRNAs such as VEGF. Our finding suggests that c-Src could be an important target of therapy for tumors that express high levels of $\alpha 6 \beta 4$.

\section{Methods}

\section{Cell lines and cultures}

The MDA-MB-231 human breast carcinoma cells and MDA-MB-435 human cancer cells were obtained from the Lombardi Breast Cancer Depository at Georgetown University. The generation of MDA-MB-435 subclones (MDA-MB-435/mock (vector only) and MDA-MB-435/ 

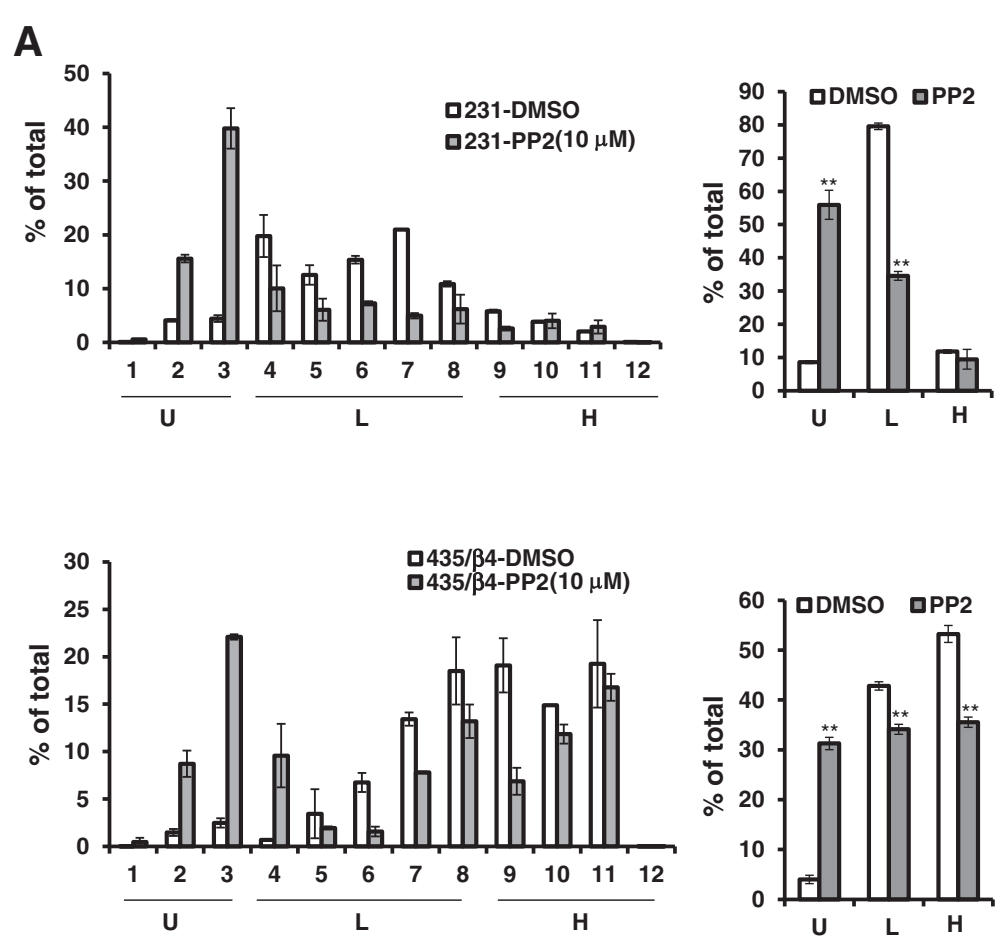

B
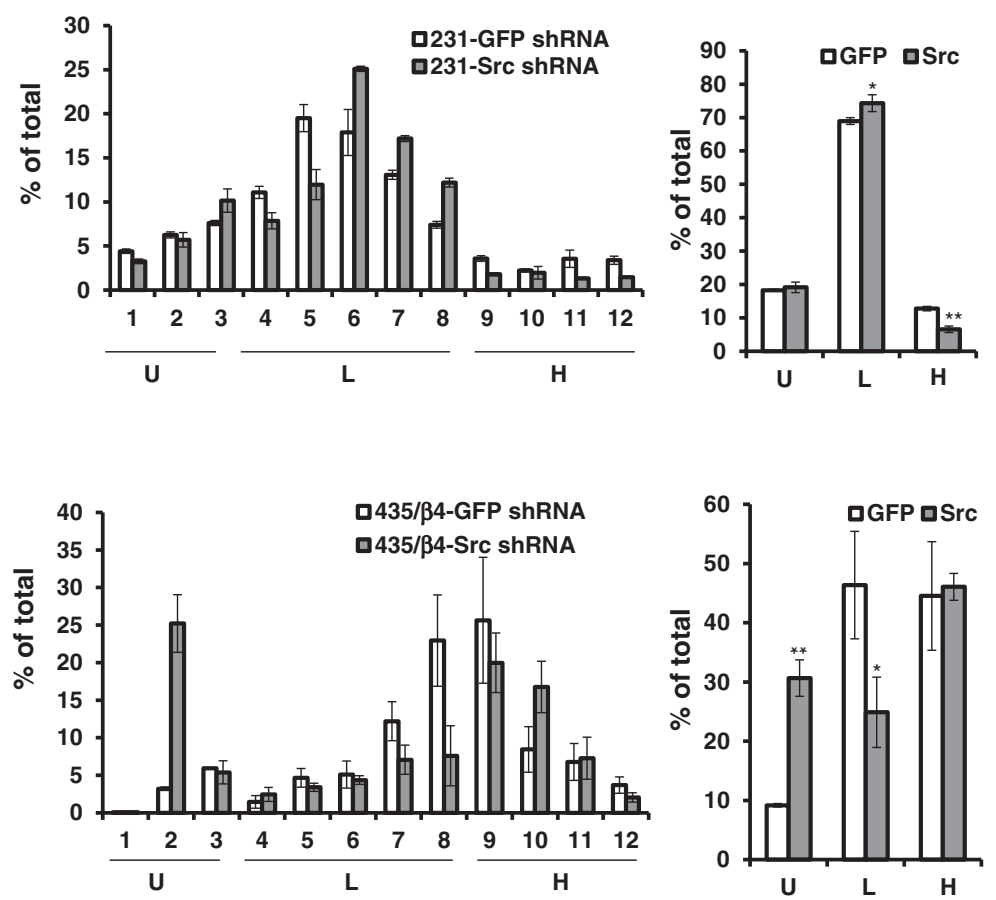

Figure 4 Src activity is required for $\mathbf{a} 6 \beta 4$ dependent VEGF translation. Whole cell lysates were prepared from MDA-MB-231 cells and MDAMB-435/B4 cells treated with DMSO or $10 \mu \mathrm{M}$ PP2 overnight (A) and infected with GFP or c-Src shRNA (B). The relative VEGF mRNA content of each sucrose gradient fraction was measured by Real time PCR and normalized to GFP mRNA (external control) as described in the Methods. The data are represented as the mean ratio of VEGF to $\beta$ - actin mRNA ( \pm SD) obtained from triplicate samples. The statistical analysis was done using Student's $t$-test. ${ }^{*} P<0.05,{ }^{* *} P<0.01$. U, untranslated complexes (fractions \#1-3); L, light polyribosomes (fractions \#4-8); H, heavy polyribosomes (fractions \#9-12). 

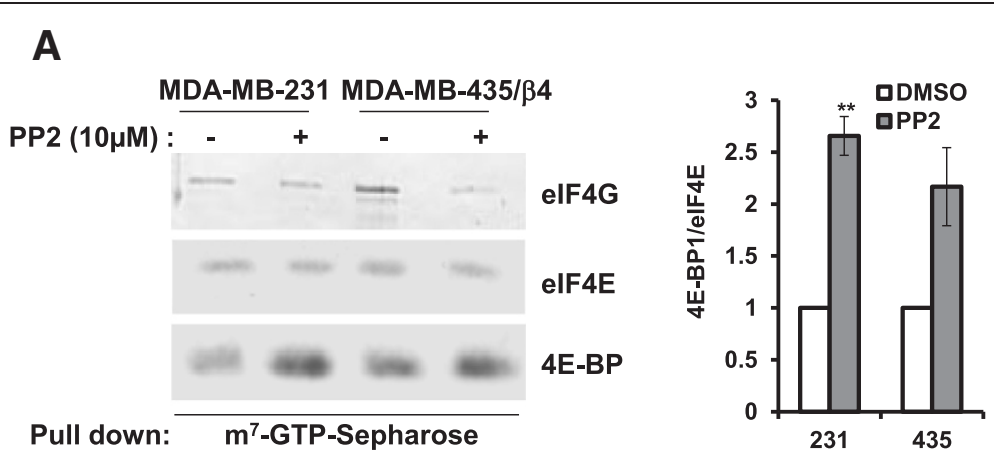

B
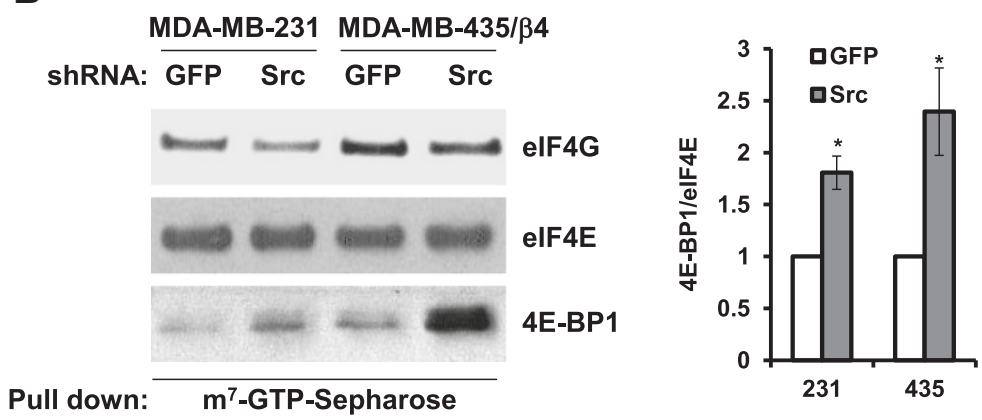

Figure 5 Src activity is required for elF-4 F complex. MDA-MB-231 cells and MDA-MB-435/ $\beta 4$ cells treated with DMSO or PP2 (A) and infected with either GFP- or Src-shRNA (B) were lysed and then incubated with $\mathrm{m}^{7} \mathrm{GTP}$-Sepharose beads. The eluted proteins were analyzed by immunoblotting with antibodies against elF4G, elF4E and 4E-BP. The graphs on the right side of each panel represent the mean ratio of 4E-BP1 to elF4E in triplicate samples ( $\pm \mathrm{SD}$ ). The statistical analysis was done using Student's $t$-test. ${ }^{*} P<0.05,{ }^{* *} P<0.01$.

B4 ( 34 over-expression)) was done as previously described [13]. MDA-MB-231 cells were stably infected with lentivirus that expressed shRNA targeted against $\beta 4$ integrin or Src and MDA-MB-435/ $\beta 4$ cells were infected against Src as previously described [20]. GFP shRNA was used as control and puromycin $(2 \mu \mathrm{g} / \mathrm{ml})$ was used for the selection of infected cells. Cells were maintained in Dulbecco's modified Eagle's medium (DMEM)/low glucose (Hyclone, Logan, UT) supplemented with 10\% fetal bovine serum and 1\% penicillin-streptomycin (Gibco, Carlsbad, CA).

\section{Antibodies and reagents}

The integrin $\beta 4$ (clone H-101) and actin (clone C-11) antibodies were purchased from Santa Cruz Biotechnology (Santa Cruz, CA), and the p-mTOR (S2448), p-Src (Y416), p-Akt (S473), p-S6 ribosomal protein (S235/236), p-4EBP1 (S65), 4E-BP1, mTOR, Src (clone 36D10), and Akt antibodies were obtained from Cell Signaling Technology (Beverly, MA). Also, integrin B4 (Y1494, phosphospecific) antibody was obtained from ECM bioscience (Versailles, KY) and PP2 (Src kinase inhibitor) was purchased from EMD chemicals Inc. (San Diego, CA). The antibodies against eIF4G and eIF4E were kindly provided by Dr. Rhoads (LSUHSC, Shreveport). For the pharmacological inhibition, cells were incubated with or without
10-50 $\mu \mathrm{M}$ PP2 for 24 hours before lysis for Western blot analysis.

\section{Western blot analysis}

Cells were lysed using $50 \mathrm{mM}$ Tris buffer, $\mathrm{pH} 7.4$, containing $150 \mathrm{mM} \mathrm{NaCl}, 1 \% \mathrm{NP}-40,0.5 \%$ sodium deoxycholate, $0.1 \%$ SDS, $1 \mathrm{mM}$ sodium orthovanadate, $5 \mathrm{mM}$ EDTA, $1 \mathrm{mM}$ phenylmethylsulfonyl fluoride, and $1 \%$ protease inhibitor (Pierce, Rockford, IL) and scraped, collected, and then protein concentration was determined using BCA protein assay kit (Pierce, Rockford, IL). Total protein was resolved on the $4-20 \%$ gradient SDS-PAGE, transferred to polyvinylidene fluoride membranes and incubated with a primary antibody. After three 10 min washes in $50 \mathrm{mM}$ Tris buffer, $\mathrm{pH} 7.5$, containing $0.15 \mathrm{M} \mathrm{NaCl}$ and $0.1 \%$ Tween-20, protein was detected, in turn, by means of a peroxidase - or alkaline phoaphatase - conjugated secondary antibody and visualized using the Luminol and Oxidizing solutions (Boston Bioproducts, Worcester, MA) or BCIP/NBT Color development substrate (Promega, Madison, WI).

\section{Ribosome fractionation}

The MDA-MB-231 cells and MDA-MB- $435 / \beta 4$ cells were maintained in low serum $(0.5 \%$ FBS $)$ medium and then pretreated with $0.1 \%$ DMSO (as a solvent for PP2) 
or $10 \mu \mathrm{M}$ PP2 for $24 \mathrm{~h}$. The MDA-MB-231 cells and MDA-MB-435/ $\beta 4$ cells were infected with lentivirouses expressing GFP- or Src shRNA. Before cell lysis, cells were treated with $50 \mu \mathrm{g} / \mathrm{ml}$ cycloheximide (VWR) and then incubated for $5-10 \mathrm{~min}$ at $37^{\circ} \mathrm{C}$. After washing with PBS containing $100 \mu \mathrm{g} / \mathrm{ml}$ cycloheximide, cells were lysed in $0.5 \mathrm{ml}$ buffer containing $50 \mathrm{mM}$ Tris- $\mathrm{HCl}$ (pH 7.5), $100 \mathrm{mM} \mathrm{KCl}, 10 \mathrm{mM} \mathrm{MgCl}_{2}, 0.5 \% \mathrm{NP}-40$, $2 \mathrm{mM}$ DTT, $100 \mu \mathrm{g} / \mathrm{ml}$ cycloheximide, $50 \mu \mathrm{g} / \mathrm{ml}$ heparin, RNasin $0.5 \mathrm{U} / \mu \mathrm{l}$ (Applied Biosystems), and Complete ${ }^{\mathrm{Tm}}$ EDTA-free protease inhibitor cocktail (Roche), incubated on ice for $10 \mathrm{~min}$ and centrifuged for $5 \mathrm{~min}$ at 10,000 $\times \mathrm{g}$, $4^{\circ} \mathrm{C}$. The supernatants were collected and frozen at $-80^{\circ} \mathrm{C}$. One hundred $\mu \mathrm{g}$ aliquots of total lysates were used for $\mathrm{m}^{7}$ GTP-Sepharose binding experiments. An equal volume of lysate was applied to a 15 to $45 \%$ (w/v) sucrose gradient containing $100 \mu \mathrm{g} / \mathrm{ml}$ cycloheximide and then centrifuged in a Beckman SW41Ti rotor at 38,000 rpm at $4^{\circ} \mathrm{C}$ for $3 \mathrm{~h}$. Gradients were fractionated $(1 \mathrm{ml})$ and then monitored for absorbency at $254 \mathrm{~nm}$ using an ISCO syringe pump with UV-6 detector.

\section{RNA preparation and quantitative real time PCR}

Before RNA isolation, four hundred aliquots from each fraction after ribosome fractionation were spiked with $100 \mathrm{pg}$ of GFP mRNA (internal control). Then, the RNA was purified from using an E.Z.N.A. Total RNA Kit (Omega bio-tek) according to manufacturer's instructions. Reverse transcription was performed with random primers and reverse transcriptase from the TaqMan ${ }^{\circ} \mathrm{Re}-$ verse Transcription Reagents kit (Applied Biosystems) following the manufacturer's protocol. Quantitative real time PCR was used to measure the GFP and VEGF mRNAs level in each fraction. Amplification and detection were performed using the iCycler IQ Real-time PCR detection system with IQ ${ }^{\mathrm{Tm}}$ SYBRgreen Supermix (BioRad). The VEGF mRNA levels were normalized with the GFP internal control. Then, relative amount of VEGF in each fraction was expressed as a percentage of the sum of this mRNA in all fractions. To assist statistical significance of the changes in the VEGF mRNA redistribution along the sucrose density gradients, the percentage of VEGF mRNA co-sedimented with untranslated complexes (U, fractions \#1-3), light polyribosomes, containing weakly translated mRNA (fractions \#4-8) or heavy polyribosomes, containing efficiently translated mRNAs ( $\mathrm{H}$, fractions \#912 ), was calculated as a sum of VEGF mRNA in the corresponding fractions from the original data.

\section{Protein binding assays on $\mathrm{m}^{7} \mathrm{GTP}$-sepharose}

One hundred $\mu \mathrm{g}$ of lysates were prepared as described in the "Ribosome Fractionation" section and then diluted in equal volume of buffer containing $50 \mathrm{mM}$ Tris- $\mathrm{HCl}$ (pH 7.5) and $2 \mathrm{mM}$ DTT. The samples were mixed with
$50 \mu \mathrm{l} \mathrm{m}^{7}$ GTP-Sepharose (GE Healthcare), 50\% slurry in buffer containing $20 \mathrm{mM}$ Tris- $\mathrm{HCl}$ (pH 7.5), $100 \mathrm{mM}$ $\mathrm{KCl}, 1 \mathrm{mM}$ DTT, and 10\% (v/v) glycerol. After $2 \mathrm{~h}$ incubation at $4^{\circ} \mathrm{C}$ with rotation, the resin was washed three times with 200- $\mu$ l aliquots of buffer B. Proteins were eluted in $20 \mu \mathrm{l}$ SDS-electrophoresis buffer and analyzed by Western blotting. To assist statistical significance of the changes in the eIF4E and 4EBP1 binding, the bands of corresponding proteins were scanned and analyzed with ImageQuant TL software.

\section{Authors' contribution}

YHS prepared for Figures 1, 2 and 3 and wrote introduction, results and methods section. NK prepared for Figures 4 and 5. THK contributed to Figures 1 and 2. JC designed and monitored the whole assays listed in the manuscript, wrote abstract and discussion, and edited the writing in the entire manuscript. All authors reviewed the manuscript. All authors read and approved the final manuscript.

\section{Acknowledgements}

This study is supported by American Cancer Society (RSG-09-091-01-CSM: JC) and NIH-NCI (R01CA163657-01A1: JC). We thank Dr. Rhoads (LSUHSC-Shreveport) for providing antibodies against elF4G and elF4E.

\section{Author details}

'Department of Physiology and Stephenson Cancer Center, The University of Oklahoma Health Science Center, Oklahoma City, Oklahoma 73104, USA. ${ }^{2}$ Departments of Emergency Medicine and Biochemistry, Louisiana State University Health Science Center, Shreveport, Louisiana 71130, USA. ${ }^{3}$ The James Comprehensive Cancer Center, The Ohio State University Wexner Medical Center, Columbus, Ohio 43210, USA.

\section{Received: 10 June 2013 Accepted: 25 October 2013}

Published: 1 November 2013

\section{References}

1. Hanahan D, Weinberg RA: The hallmarks of cancer. Cell 2000, 100:57-70.

2. Graff JR, Zimmer SG: Translational control and metastatic progression: enhanced activity of the mRNA cap-binding protein elF-4E selectively enhances translation of metastasis-related mRNAs. Clin Exp Metastasis 2003, 20:265-273.

3. Sonenberg N, Gingras AC: The mRNA 5 ' cap-binding protein elF4E and control of cell growth. Curr Opin Cell Biol 1998, 10:268-275.

4. Goodfellow IG, Roberts LO: Eukaryotic initiation factor 4E. Int J Biochem Cell Biol 2008, 40:2675-2680.

5. Raught $B$, Gingras AC: elF4E activity is regulated at multiple levels. Int J Biochem Cell Biol 1999, 31:43-57.

6. Svitkin YV, Herdy B, Costa-Mattioli M, Gingras A-C, Raught B, Sonenberg N: Eukaryotic translation initiation factor $4 \mathrm{E}$ availability controls the switch between cap-dependent and internal ribosomal entry site-mediated translation. Mol Cell Biol 2005, 25:10556-10565.

7. Wang $X$, Proud CG: The mTOR pathway in the control of protein synthesis. Physiol Bethesda Md 2006, 21:362-369.

8. Averous J, Proud CG: When translation meets transformation: the mTOR story. Oncogene 2006, 25:6423-6435.

9. De Benedetti A, Graff JR: elF-4E expression and its role in malignancies and metastases. Oncogene 2004, 23:3189-3199.

10. Graff JR, Konicek BW, Lynch RL, Dumstorf CA, Dowless MS, McNulty AM, Parsons SH, Brail LH, Colligan BM, Koop JW, Hurst BM, Deddens JA, Neubauer BL, Stancato LF, Carter HW, Douglass LE, Carter JH: elF4E activation is commonly elevated in advanced human prostate cancers and significantly related to reduced patient survival. Cancer Res 2009, 69:3866-3873.

11. Bianchini A, Loiarro M, Bielli P, Busà R, Paronetto MP, Loreni F, Geremia R, Sette C: Phosphorylation of elF4E by MNKs supports protein synthesis, cell cycle progression and proliferation in prostate cancer cells. Carcinogenesis 2008, 29:2279-2288. 
12. Chung J, Kim TH: Integrin-dependent translational control: Implication in cancer progression. Microsc Res Tech 2008, 71:380-386.

13. Chung J, Bachelder RE, Lipscomb EA, Shaw LM, Mercurio AM: Integrin (alpha 6 beta 4) regulation of elF-4E activity and VEGF translation: a survival mechanism for carcinoma cells. J Cell Biol 2002, 158:165-174.

14. Dutta U, Shaw LM: A Key tyrosine (Y1494) in the $\beta 4$ integrin regulates multiple signaling pathways important for tumor development and progression. Cancer Res 2008, 68:8779-8787.

15. Bertotti A, Comoglio PM, Trusolino L: $\beta 4$ integrin activates a Shp2-Src signaling pathway that sustains HGF-induced anchorage-independent growth. J Cell Biol 2006, 175:993-1003.

16. Kim LC, Song L, Haura EB: Src kinases as therapeutic targets for cancer. Nat Rev Clin Oncol 2009, 6:587-595.

17. Irby RB, Yeatman TJ: Role of Src expression and activation in human cancer. Oncogene 2000, 19:5636-5642.

18. Sudhagar S, Sathya S, Lakshmi BS: Rapid non-genomic signalling by $17 \beta-$ oestradiol through c-Src involves mTOR-dependent expression of HIF-1a in breast cancer cells. Br J Cancer 2011, 105:953-960.

19. Karni R, Gus Y, Dor Y, Meyuhas O, Levitzki A: Active Src elevates the expression of beta-catenin by enhancement of cap-dependent translation. Mol Cell Biol 2005, 25:5031-5039.

20. Kim TH, Kim HI, Soung YH, Shaw LA, Chung J: Integrin (alpha6beta4) signals through Src to increase expression of S100A4, a metastasispromoting factor: implications for cancer cell invasion. Mol Cancer Res MCR 2009, 7:1605-1612.

21. Ma XM, Blenis J: Molecular mechanisms of mTOR-mediated translational control. Nat Rev Mol Cell Biol 2009, 10:307-318.

22. Dancey J: mTOR signaling and drug development in cancer. Nat Rev Clin Oncol 2010, 7:209-219.

23. Yang X, Dutta U, Shaw LM: SHP2 mediates the localized activation of Fyn downstream of the a6 $\beta 4$ integrin to promote carcinoma invasion. Mol Cell Biol 2010, 30:5306-5317.

24. Abdel-Ghany M, Cheng H-C, Elble RC, Pauli BU: Focal adhesion kinase activated by beta(4) integrin ligation to mCLCA1 mediates early metastatic growth. J Biol Chem 2002, 277:34391-34400

25. Wu L, Bernard-Trifilo JA, Lim Y, Lim S-T, Mitra SK, Unyu S, Chen M, Pallen CJ, Cheung N-K, Mikolon D, Mielgo A, Stupack DG, Schlaepfer DD: Distinct FAKSrc activation events promote alpha5beta1 and alpha4beta1 integrinstimulated neuroblastoma cell motility. Oncogene 2008, 27:1439-1448.

26. Jacinto E, Facchinetti V, Liu D, Soto N, Wei S, Jung SY, Huang Q, Qin J, Su B: SIN1/MIP1 maintains rictor-mTOR complex integrity and regulates Akt phosphorylation and substrate specificity. Cell 2006, 127:125-137.

27. Liu L, Parent CA: Review series: TOR kinase complexes and cell migration. J Cell Biol 2011, 194:815-824.

28. Vojtechová M, Turecková J, Kucerová D, Sloncová E, Vachtenheim J, Tuhácková Z: Regulation of mTORC1 signaling by Src kinase activity is Akt1-independent in RSV-transformed cells. Neoplasia New York N 2008, 10:99-107.

29. Haynes MP, Li L, Sinha D, Russell KS, Hisamoto K, Baron R, Collinge M, Sessa WC, Bender JR: Src kinase mediates phosphatidylinositol 3-kinase/Aktdependent rapid endothelial nitric-oxide synthase activation by estrogen. J Biol Chem 2003, 278:2118-2123.

30. Li JD, Feng W, Gallup M, Kim JH, Gum J, Kim Y, Basbaum C: Activation of NF-kappaB via a Src-dependent Ras-MAPK-pp90rsk pathway is required for Pseudomonas aeruginosa-induced mucin overproduction in epithelial cells. Proc Natl Acad Sci U S A 1998, 95:5718-5723.

31. Lipscomb EA, Mercurio AM: Mobilization and activation of a signaling competent alpha6beta4integrin underlies its contribution to carcinoma progression. Cancer Metastasis Rev 2005, 24:413-423.

32. Shaw LM, Rabinovitz I, Wang HH-F, Toker A, Mercurio AM: Activation of phosphoinositide $3-\mathrm{OH}$ kinase by the a6 $\beta 4$ integrin promotes carcinoma invasion. Cell 1997, 91:949-960.

33. Trusolino L, Bertotti A, Comoglio PM: A signaling adapter function for alpha6beta4 integrin in the control of HGF-dependent invasive growth. Cell 2001, 107:643-654

\section{Submit your next manuscript to BioMed Central and take full advantage of:}

- Convenient online submission

- Thorough peer review

- No space constraints or color figure charges

- Immediate publication on acceptance

- Inclusion in PubMed, CAS, Scopus and Google Scholar

- Research which is freely available for redistribution 